\title{
The Physiotherapist \\ in an \\ Intensive Care Unit
}

\section{by}

\author{
C. J. MIENY, Ch.M., F.R.C.S., F.C.S.(S.A.). \\ Senior Surgeon Johannesburg General Hospital
}

Intensive Care Units are being established in most big hospitals in the world today. The reasons for this development are twofold. Concentration of specialized nurses and equipment, and unification of the efforts of various specialist groups, both medical and para-medical, necessary for the care of patients after major trauma, major surgery and medical emergencies, such as respiratory failure, renal failure and coronary thrombosis.

Chest complications and deep vein thrombosis are common in patients in an Intensive Care Ward because many of the predisposing factors are accentuated (Table I).

TABLE I.

\section{PREDISPOSING FACTORS}

Age

Smoking

Existing chest disease - previous D.V.T.

Lack of pre-operative preparation

Type of operation - upper abdominal

Delay in mobilisation

Dehydration and distension

To illustrate this an analysis of admissions to the Surgical Intensive Care Ward at the Johannesburg General Hospital for one year will be presented.

It can be seen in Table II that the majority of cases were older than 50 years.

Although most cases stayed in the unit for a few days only, 42 per cent remained for longer than a week. Fortyfour patients were admitted with severe trauma, 67 for surgical emergencies and 107 after elective surgery. The other 15 patients were kidney transplants and other miscellaneous conditions.

TABLE II.

ADMISSION FOR ONE YEAR
Sex
MALE.. $\quad$ No.
FEMALE $\quad . \quad 92$
TOTAL
AGE-60\% over 50

TABLE III.

TYPE OF CASES

\begin{tabular}{l|r|r|c}
\hline & No. & IPPR* & Mortality \\
\cline { 2 - 4 } Upper abdominal surgery & 101 & 7 & 18 \\
Major arterial surgery & 22 & 3 & 7 \\
Severe head injuries & 20 & 15 & 13 \\
Major viscus injuries & 18 & 12 & 4 \\
\hline
\end{tabular}

*IPPR $=$ Intermittent positive pressure respiration.

The serious condition of most of these patients is stressed in Table III. Of the 161 patients analyzed, 37 needed intermittent positive pressure respiration and there was a mortality of 26 per cent.

Forty-five per cent of all cases developed chest complications and eight per cent developed deep vein thrombosis.

\section{DISCUSSION}

From an analysis of these facts it becomes obvious that all the patients warranting admission to this unit needed not only urgent treatment from medical and nursing staff, but also from the Department of Physiotherapy.

Patients were admitted to the unit at all hours of the day or night which made it imperative that emergency physiotherapy should be available at all times.

The serious and urgent nature of most of these cases made it necessary that medical officers, intensive care nurses and physiotherapists should discuss individual cases together to plan an intensive course of treatment.

Physiotherapists must be prepared to join these highly specialized teams by supplying full-time services with staff familiar with the highly sophisticated equipment in such a unit, and trained in the care of these severely ill patients.

\section{ACKNOWLEDGEMENT}

I wish to thank Dr. Kenny, Medical Superintendent of the Johannesburg General Hospital, for permission to publish this short paper. 